3

4

Article type : Original

6

Corresponding author mail id:- melissar@unimelb.edu.au

9

\title{
ARE YOUNG CHILDREN WITH ASTHMA MORE LIKELY TO BE LESS PHYSICALLY ACTIVE?
}

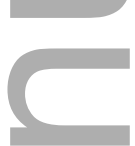

CONFLICT OF INTEREST: The authors declare that they have no known competing financial interests or personal relationships that could have appeared to influence the work reported in this paper.

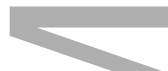

FUNDING SOURCE DECLARATION: HealthNuts was supported by the NHMRC (Project Grants 491233 and 1006215), Ilhan Food Allergy Foundation, AnaphylaxiStop and the Charles and Sylvia Viertel Medical Research Foundation. RLP, JJK, AJL, SCD hold or held NHMRC fellowships or other grant funding during data collection for this paper. Research at the Murdoch Children's Research Institute is supported by the Victorian Government's Operational Infrastructure Support Programme.

\section{ABSTRACT:}

Background: Previous research suggests that children who experience asthma may be less physically active, however results have been inconclusive. This study aimed to investigate whether the presence of asthma or wheeze is associated with lower physical activity levels in children, and whether sex, body mass index or earlier asthma or wheeze status modifies the association.

This is the author manuscript accepted for publication and has undergone full peer review but has not been through the copyediting, typesetting, pagination and proofreading process, which may lead to differences between this version and the Version of Record. Please cite this article as doi: $10.1111 /$ PAI.13383

This article is protected by copyright. All rights reserved 
Methods: This study was conducted in 391 HealthNuts participants in Melbourne, Australia. Asthma and wheeze data were collected via questionnaire at age 4 and 6 and physical activity was measured through accelerometry. Using adjusted linear regression models, the cross-sectional and longitudinal associations were investigated.

Results: There was no evidence of a difference in time spent in moderate-to-vigorous physical activity (MVPA) at age 6 years between children with and without asthma at age 4; children with asthma spent 8.3 minutes more time physically active per day $(95 \% \mathrm{Cl}:-5.6,22.1, \mathrm{p}=0.24)$ than children without asthma. Similar results were seen for children with current wheeze (5.8 minutes per day more, $95 \% \mathrm{Cl}:-5.9,17.5, \mathrm{p}=0.33$ ) or ever wheeze or asthma ( $7.7 \mathrm{~min}$ per day more, $95 \% \mathrm{Cl}$ : $4.8,20.2, p=0.23$ ) at age 4 years. Comparable null results were observed in the cross-sectional analyses. Interaction with BMI could not be assessed, however, previous asthma or wheeze status and sex were not found to modify these associations.

Conclusion: This analysis found no evidence of asthma hindering physical activity in these young children. These results are encouraging, as they indicate that the Australian asthma and physical activity public health campaigns are being effectively communicated and adopted by the public.

KEY MESSAGE: This prospective study investigates the association between asthma at 4 years and physical activity at 6 years. It provides evidence that asthma does not hinder subsequent moderateto-vigorous physical activity in these young, Australian children. It provides evidence of a successful management model used in Australia that can and should be adopted by other settings wishing to address the issue of insufficient physical activity in children with asthma.

KEYWORDS: Asthma, Accelerometry, Children, Cohort, Physical activity, Wheeze

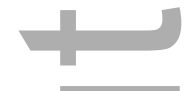

\section{INTRODUCTION}

Physical inactivity is a leading risk factor for the development of a variety of non-communicable diseases. Since physical activity tracks moderately through life, the promotion of a physically active lifestyle from a young age may be important and beneficial for future health (1). For this reason, the World Health Organization (WHO) and other national health guidelines currently recommend that children and adolescents between the ages of 5 and 17 years engage in a minimum of 60 minutes of 
moderate-to-vigorous physical activity (MVPA) daily $(2,3)$. However, numerous international studies have demonstrated that large proportions of children and adolescents fail to meet the current physical activity recommendations $(4,5)$. It is believed that physical activity engagement decreases with age, and that subgroups of children are more likely to be insufficiently active than others.

Some studies have found that children who experience asthma may lead less physically active lives (6), however these results are inconsistent (7). Globally, asthma is the most common chronic condition in childhood, adversely affecting quality of life and constituting an important global health problem in childhood (8). Despite asthma guidelines encouraging physical activity as a nonpharmaceutical intervention for asthma, strenuous physical activity is a known trigger for asthma exacerbations (8). As such, some studies have found that children with asthma avoid physical activity for fear of triggering their asthma symptoms, or due to a fear of being mocked or stigmatised for these symptoms (9). Another study found that parents may impose physical activity restrictions on children with asthma (10).

Our recent systematic review concluded that children with asthma were equally as physically active as their unaffected peers (7). This finding was based mainly on cross-sectional studies as only one cohort study to date had been published (11). Therefore, the present study aimed to investigate the longitudinal relationship between asthma and wheeze at age 4 and objectively measured physical activity in children aged 6 years. The cross-sectional relationship at the age of 6 years was also examined, and whether a change in asthma status from age 4 to 6 is associated with physical activity. Finally, we explored whether BMI and sex modified the association between asthma and physical activity.

\section{METHODOLOGY}

The HealthNuts study, is a population-based study of allergic disease burden in over 5,000 children (12). Between September 2007 and August 2011, children aged between 11 and 15 months who presented for routine 12-month vaccinations at immunization clinics within a $70 \mathrm{~km}$ radius of the Melbourne central business district were approached to participate (13). The cohort has been followed up twice, first between 2010 - 2014 and then between 2012 - 2016, when the children were aged 4 and 6 , respectively. At each follow up, caregivers were invited to complete the study questionnaire, and at age 6, were invited for a clinical assessment (13). Ethical approval was obtained from the Human Research Ethics Committee (HREC) of the Office for Children, Government 
of Victoria (ref. no. CDF/07/492), Department of Human Services, Government of Victoria (ref. no. 10/07) and The Royal Children's Hospital HREC (ref. no. 27047 and ref. no.32294).

Exposure variables were taken from the 4 and 6 year follow ups of the HealthNuts questionnaire. Standardized questions on asthma and wheeze from the validated International Study of Asthma and Allergies in Childhood (ISAAC) were used $(13,14)$. For this analysis, current asthma was defined as parental report of ever having doctor-diagnosed asthma and at least one of parent-reported wheeze or use of asthma medication in the past 12 months (14). Current wheeze was defined as parental report of any wheezing in the last 12 months (15). Ever wheeze or asthma was defined as a parental report of ever having had doctor-diagnosed asthma or wheeze at 4 and/or 6 years.

Participants who attended the 6 year follow up clinical appointment from March 2015 onward were asked to wear the waterproof GENEActiv (Gravity Estimator of Normal Everyday Activity, ActivInsights Ltd, Cambridgeshire, UK) triaxial accelerometer watch on the wrist of their nondominant hand 24 hours per day for 8 consecutive days, including during sleep, while swimming and at bath time. Parents were given instructions for the use of these devices and were asked to note the child's waking and bedtime and to briefly describe the child's activities per day on the paper log provided. Furthermore, they were asked to note times when the watch was removed and replaced, and the reasons for device removal.

For this analysis, activity was sampled at $100 \mathrm{~Hz}$ then collapsed into 60-s epochs. Participant accelerometry files and paper log were combined, and activity cut points were applied using custom Matlab software. Data were then manually inspected, correcting for unreported periods of nonwear, and re-categorising documented non-wear as time spent in MVPA where the physical activity logs indicated that the device was removed for reasons pertaining to sport participation. Individual days containing less than 16 hours of wear within a 24-hour period, or less than 10 hours of wake wear time were excluded from analysis. Participants with less than 4 valid days, or with no weekend days of valid accelerometry, were excluded from analysis. Further detail of the accelerometry processing methodology is reported elsewhere (16).

The primary outcome of this analysis was daily minutes spent in MVPA, as measured by accelerometry at age 6 years, where MVPA was defined as $>4350$ g.min, as per the cut-offs presented by Phillips et al (17).

Potential confounders were identified from the existing scientific literature and selected for inclusion in these analyses based on a directed acyclic graph (DAG; Supplementary Figure). Sex, BMI, the presence of older siblings and familial history of allergy and asthma data were collected via 
questionnaire at the HealthNuts follow ups (i.e. ages 1and 4 years). The Socio-Economic Indexes for Areas (SEIFA) was used as a proxy for socioeconomic status. Based on home postcode, each participant is allocated a SEIFA index of relative socioeconomic advantage or disadvantage, derived from the 2006 Australian census data (18). Participant BMI at age 4 was calculated from parentreported height and weight and then categorised as "underweight", "normal weight" or "overweight" based on age appropriate cut-offs (19).

\section{$\underline{\text { Statistical analysis }}$}

All statistical analyses were performed using Stata/MP 15.1 (StataCorp LLC, College Station, TX, USA). Descriptive statistics of the study sample are presented. Associations between individual exposures and MVPA were analysed in univariate linear regression models first, and then in multivariate linear regression models with adjustment for the confounders selected based on the DAG.

Prior to an investigation of effect modification by sex, BMI, or asthma or wheeze at age 4, the number of individuals within each stratum was considered. Where small numbers were found within strata, the investigation was not further pursued, however, where numbers permitted, potential effect modification was assessed by fitting individual interaction terms in the multivariate regression models and comparing models using Likelihood Ratio Tests. Stratified results were presented if the $p$ value for interaction was less than or equal to 0.05 .

\section{RESULTS}

Of those children who attended the 6 year clinical follow up, 1709 children had a full assessment after March 2015 and were invited to participate in the accelerometry testing. Accelerometers were sent to $682(40 \%)$ of these children, and data were returned for 495 participants. Of these, 104 files were excluded because they did not contain sufficient valid data or were corrupted. Hence, this study analysed valid data from a sample of 391 children (Figure 1).

In this study sample, $50.6 \%$ of children were male and $48.3 \%$ were female (Table 1 ). The proportion of children who experienced wheeze was $12.8 \%$ at age 4 years and $17.4 \%$ at age 6 years. The proportion of children with current asthma was $8.7 \%$ at age 4 and $12.5 \%$ at 6 years. At age 6 , the mean [standard deviation] time spent in MVPA for all HealthNuts children was 98 [35] min per day, and on average boys spent more time in MVPA than girls (111 [35] vs. 85 [30] min per day, respectively). Overall, $88.5 \%$ ( $82 \%$ girls and $95 \%$ of boys) of the study children met the WHO recommendation of 60 min of MVPA per day. 
139 Children with current asthma at age 4 participated in an average of 8.3 (95\% Confidence Interval $140(\mathrm{Cl})::-5.6,22.1, \mathrm{p}=0.24)$ min more MVPA per day at age 6 than children without asthma (Table 2). 141 Similarly, there were no associations seen for current wheeze $(5.8 \mathrm{~min} 95 \% \mathrm{Cl}:-5.9,17.5, \mathrm{p}=0.33)$ or 142 ever wheeze or asthma at age 4 years $(7.7 \min 95 \% \mathrm{Cl}:-4.8,20.2, \mathrm{p}=0.23)$ for time spent in MVPA at 1436 years.

Association between exposures at age 6 and physical activity at age 6

145 Children who experienced current asthma at age 6 years participated in an average of 2.9 min more 146 MVPA per day $(95 \% \mathrm{Cl}:-12.8,18.6)$ than those who did not experience current asthma (Table 2). 147 Similarly, children who experienced current wheeze at 6 years spent an average of 1.3 (95\% Cl: 148 13.2, 10.6) min less in MVPA than those without current wheeze and children with a history of asthma or wheeze spent an average of $5.3(95 \% \mathrm{Cl}:-7.4,17.9)$ more minutes in MVPA than their peers, with no evidence of a difference between these groups $(p=0.72, p=0.83$ and $p=0.41$, respectively).

Investigation of effect modification

The small number of observations within some strata prohibited the investigation of effect modification by BMI at both ages (Supplementary Table 1-3). However, likelihood ratio testing for interaction found no evidence of effect modification by sex for any of the asthma/wheeze variables at 4 or 6 years, on time spent in MVPA (all p-values for interaction $>0.3$ ) (Table 2). Similarly, there was no evidence of effect modification between exposure status at age 4 and either current asthma $(p=0.17)$, current wheeze $(p=0.59)$, or ever asthma or wheeze $(p=0.70)$.

\section{DISCUSSION}

This study is among the first to look at the longitudinal relationship between asthma and wheeze and objectively measured MVPA in a population of young children. We found no evidence of associations between current asthma, current wheeze, or a history of ever having asthma and wheeze at 4 or 6 years and MVPA as measured by accelerometer at 6 years of age. Statistical tests for interaction also found no evidence for effect modification by either sex, or asthma or wheeze status at 4 years. We were unable to explore effect modification by BMI due to insufficient power. Within this sample, the majority (88.5\%) of children met the WHO recommendation of 60 mins of MVPA per day. A greater proportion of boys (95\%) than girls (82\%) achieved this recommended amount. The mean time spent in MVPA in this study was 98 [35] minutes per day. This suggests that 
the cohort was highly active, contrary to reports of inadequate physical activity on other studies of this age group $(20,21)$.

The null results obtained in the present study are concordant with the other longitudinal study of the association between wheeze and physical activity in young children (11), and with the few additional studies that have found no longitudinal association between asthma and physical activity in youth $(22,23)$. Further, this result supports the finding of our previously published systematic review (7), and multiple studies that have found no cross-sectional associations $(24,25)$. These null results are a positive indication that, at least within Australia, these young children with asthma are not restricting their physical activity engagement on account of their asthma. Of course, these results are likely to be age dependent, with older children and adolescents partaking in less physical activity. However, these results suggest that the current asthma guidelines and public health messaging on the importance of physical activity in childhood are being effectively disseminated to, and well adopted by parents. Additionally, it signifies that general practitioners are providing children with asthma and their parents or caregivers with appropriate and effective management plans and knowledge, thus adequately controlling asthma symptoms and allowing these children to participate in physical activity without fear. These results and their implications may not be generalisable to other settings around the world, where a variety of different social, health care and economic factors may influence the relationship between asthma and physical activity.

A major strength of this analysis is the use of robust tools for the outcome measurement of MVPA. The present study is one of few that have used accelerometers to measure physical activity in children as young as six years. The use of the validated ISAAC questionnaire (26), together with objective accelerometry measurements, inspire confidence in the data. The use of an objective measurement technique is particularly important for the collection of physical activity data in children of this age, since subjective measurements of physical activity in young children may be over- or underestimated (27). Measurements by proxies such as parents or caregivers may be inaccurate; since young children tend to have brief bursts of activity that can be difficult to quantify through observation (28). An additional strength is the data drawn from a prospective, populationbased cohort of young children which enables the assessment of data in a longitudinal manner to account for the temporality of the association, unlike previous studies which have been crosssectional in nature $(25,29)$.

This study also had several shortcomings. First, the high proportion of HealthNuts children that met the WHO's physical activity recommendations may be due to potential selective participation for children who were more active. Children from higher socioeconomic status have higher levels of 
202

203

204

205

206

207

208

209

210

211

212

213

214

215

216

217

218

219

220

221

222

223

224

225

226

227

228

229

230

231

232

233

physical activity (30), this may be reflected in the current results, where families with a higher SEIFA index were found to be more likely to participate in the HealthNuts study (12). This limits the external generalisability of these results. Further, major limitations with accelerometry persist through the lack of an agreed and standardized processing, analysing and reporting method (31). For example, the threshold used to define moderate-to-vigorous physical activity can vary widely, resulting in substantially different results and conclusions (31). However, as our study focused on comparative differences in MVPA, the choice of cut point should have no effect on the findings. Secondly, when the accelerometer was removed for sport, we replaced the entire non-wear period with MVPA. This likely results in an overestimation of MVPA for these periods, since the removal period may also include time to get changed, shower etc. As a result, this could create misclassification if some participants reported significantly more sport non-wear than others. This issue is discussed in greater detail elsewhere (16), however, any misclassification is likely to be nondifferential across categories of children with and without asthma as their reporting of physical activity was independent of their knowledge of this study's research questions and exposures of interest. Finally, a substantial amount of missing data at the 4 year follow up meant there was insufficient power to present reliable results for interaction between BMI and asthma. Future longitudinal studies with greater statistical power should explore the signal for asthma and BMI in more depth.

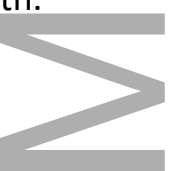

\section{CONCLUSION}

We found no evidence of either longitudinal or cross-sectional associations between current asthma, current wheeze or a history of ever having had asthma or wheeze and the amount of time spent in objectively measured moderate-to vigorous physical activity at 6 years of age. These results suggest that in this Australian setting, asthma guidelines and management strategies seem to be working effectively, so that physical activity is not restricted in young children with asthma.

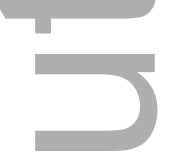

ACKNOWLEDGMENTS: We thank the parents and children who participated in the HealthNuts study as well as the staff of Melbourne's Local Government Areas for access to community Immunisation Clinics. We also thank the HealthNuts safety committee: Associate Professor Noel Cranswick (Australian Paediatric Pharmacology Research Unit, Murdoch Children's Research Institute), Dr Joanne Smart (Department of Allergy and Immunology, Royal Children's Hospital, Melbourne, Australia) and Professor Jo Douglass (Director, Department of Allergy and Immunology, Royal 

providing the allergens for SPTs. The HealthNuts investigators whose names do not appear among the list of co-authors for this paper include Anne-Louise Ponsonby, Melissa Wake, Lyle Gurrin.

237

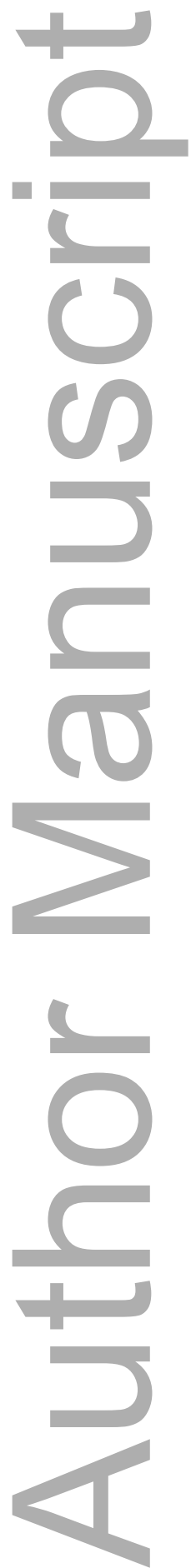


239 1. Tammelin T, Viikari JS, Raitakari OT. Tracking of physical activity from early childhood through youth into

240 adulthood. Med Sci Sports Exerc. 2014;46:955-62.

$2412 . \quad$ Organization WH. Global recommendations on physical activity for health. 2010.

242 3. Tremblay MS, Warburton DE, Janssen I, Paterson DH, Latimer AE, Rhodes RE, et al. New Canadian physical 243 activity guidelines. Applied Physiology, Nutrition, and Metabolism. 2011;36(1):36-46.

244 4. Tremblay MS, Gray CE, Akinroye K, Harrington DM, Katzmarzyk PT, Lambert EV, et al. Physical activity of children:

245 a global matrix of grades comparing 15 countries. Journal of physical activity and health. 2014;11(s1):S113-S25.

$2465 . \quad$ Jekauc D, Reimers AK, Wagner MO, Woll A. Prevalence and socio-demographic correlates of the compliance with

247 the physical activity guidelines in children and adolescents in Germany. BMC public health. 2012;12(1):714.

248 6. Lang DM, Butz AM, Duggan AK, Serwint JR. Physical activity in urban school-aged children with asthma.

249 Pediatrics. 2004;113(4):e341-6.

2507 Cassim R, Koplin JJ, Dharmage SC, Senaratna BCV, Lodge CJ, Lowe AJ, et al. The difference in amount of physical

251 activity performed by children with and without asthma: A systematic review and meta-analysis. Journal of Asthma.

252 2016:00-.

253 8. GINA. Global Strategy for Asthma Management and Prevention. 2020.

254 9. Walker TJ, Reznik M. In-school asthma management and physical activity: children's perspectives. Journal of 255 Asthma. 2014;51(8):808-13.

256 10. Dantas FM, Correia MA, Jr., Silva AR, Peixoto DM, Sarinho ES, Rizzo JA. Mothers impose physical activity

257 restrictions on their asthmatic children and adolescents: an analytical cross-sectional study. BMC public health. 258 2014;14:287.

259 11. Eijkemans M, Mommers M, de Vries SI, van Buuren S, Stafleu A, Bakker I, et al. Asthmatic symptoms, physical 260 activity, and overweight in young children: a cohort study. Pediatrics. 2008;121(3):e666-72.

261 12. Osborne N, Koplin J, Martin P, Gurrin L, Thiele L, Tang M, et al. The HealthNuts population-based study of 262 paediatric food allergy: validity, safety and acceptability. Clinical \& Experimental Allergy. 2010;40(10):1516-22.

263 13. Koplin JJ, Wake M, Dharmage SC, Matheson M, Tang ML, Gurrin LC, et al. Cohort Profile of the HealthNuts study: 264 Population prevalence and environmental/genetic predictors of food allergy. International journal of epidemiology. 265 2015:dyu261.

266 14. Peters RL, Koplin JJ, Gurrin LC, Dharmage SC, Wake M, Ponsonby A-L, et al. The prevalence of food allergy and 267 other allergic diseases in early childhood in a population-based study: HealthNuts age 4-year follow-up. Journal of Allergy 268 and Clinical Immunology. 2017.

269 15. Corbo GM, Forastiere F, De Sario M, Brunetti L, Bonci E, Bugiani M, et al. Wheeze and asthma in children: 270 associations with body mass index, sports, television viewing, and diet. Epidemiology (Cambridge, Mass). 2008;19(5):747-

27155.

272 16. Fraysse F, Grobler AC, Muller J, Wake M, Olds T. Physical activity and sedentary activity: population epidemiology 273 and concordance in Australian children aged 11-12 years and their parents. BMJ Open. 2019;9(Suppl 3):136-46.

274 17. Phillips LR, Parfitt G, Rowlands AV. Calibration of the GENEA accelerometer for assessment of physical activity 275 intensity in children. Journal of science and medicine in sport. 2013;16(2):124-8.

276 18. Pink B. An Introduction to Socio-Economic Indexes for Areas (SEIFA). Canberra, ACT: Australian Bureau of 277 Statistics, 2006. 

Pediatric obesity. 2012;7(4):284-94.

280 20. Hnatiuk JA, Salmon J, Hinkley T, Okely AD, Trost S. A review of preschool children's physical activity and sedentary time using objective measures. American journal of preventive medicine. 2014;47(4):487-97. 21. Andersen E, Borch-Jenssen J, Øvreås S, Ellingsen H, Jørgensen KA, Moser T. Objectively measured physical activity level and sedentary behavior in Norwegian children during a week in preschool. Preventive medicine reports. 2017;7:1305. asthma, eczema and obesity in children aged 12-16: an observational cohort study. BMJ open. 2019;9(1):e024858. 23. Cassim R, Milanzi E, Koplin JJ, Dharmage SC, Russell MA. Physical activity and asthma: cause or consequence? A bidirectional longitudinal analysis. Journal of epidemiology and community health. 2018:jech-2017-210287. 24. Cassim R, Dharmage SC, Koplin JJ, Milanzi E, Russell MA. Suspected asthma status and time spent in physical activity across multiple childhood age groups. Annals of allergy, asthma \& immunology: official publication of the American College of Allergy, Asthma, \& Immunology. 2018;120(2):219. 25. Pike KC, Griffiths L, Dezateux C, Pearce A. Physical activity among children with asthma: Cross-sectional analysis in the UK millennium cohort. Pediatric pulmonology. 2019;54(7):962-9. 26. Asher M, KeilU, Anderson H, Beasley R, Crane J, Martinez F, et al. International Study of Asthma and Allergies in Childhood (ISAAC): rationale and methods. European respiratory journal. 1995;8(3):483-91. sedentary behaviour: review with new data. Archives of disease in childhood. 2008;93(7):614-9. 28. Pate RR, O'NEILL JR, Mitchell J. Measurement of physical activity in preschool children. Medicine \& Science in Sports \& Exercise. 2010;42(3):508-12. 29. Koinis-Mitchell D, Kopel S, McQuaid E, Vehse N, Mitchell P, Jelalian E. Physical Activity and Asthma Outcomes in Urban Children: Differences by Ethnic Group and Weight Status. B102 DISPARITIES IN ASTHMA MANAGEMENT: American Thoracic Society; 2019. p. A4072-A.

30. Drenowatz C, Eisenmann JC, Pfeiffer KA, Welk G, Heelan K, Gentile D, et al. Influence of socio-economic status on habitual physical activity and sedentary behavior in 8-to 11-year old children. BMC public health. 2010;10(1):1-11. algorithms, and activity cut-points on estimates of child sedentary behavior and physical activity from accelerometer data.

Table 1: Comparison of descriptive characteristics of children with accelerometry data at age 6 .

\section{CHARACTERISTIC}

N (\%) OR MEAN [SD]

\section{MEASURED AT 1 YEAR}

\section{SEX,}

MALE

$198(50.7)$ 


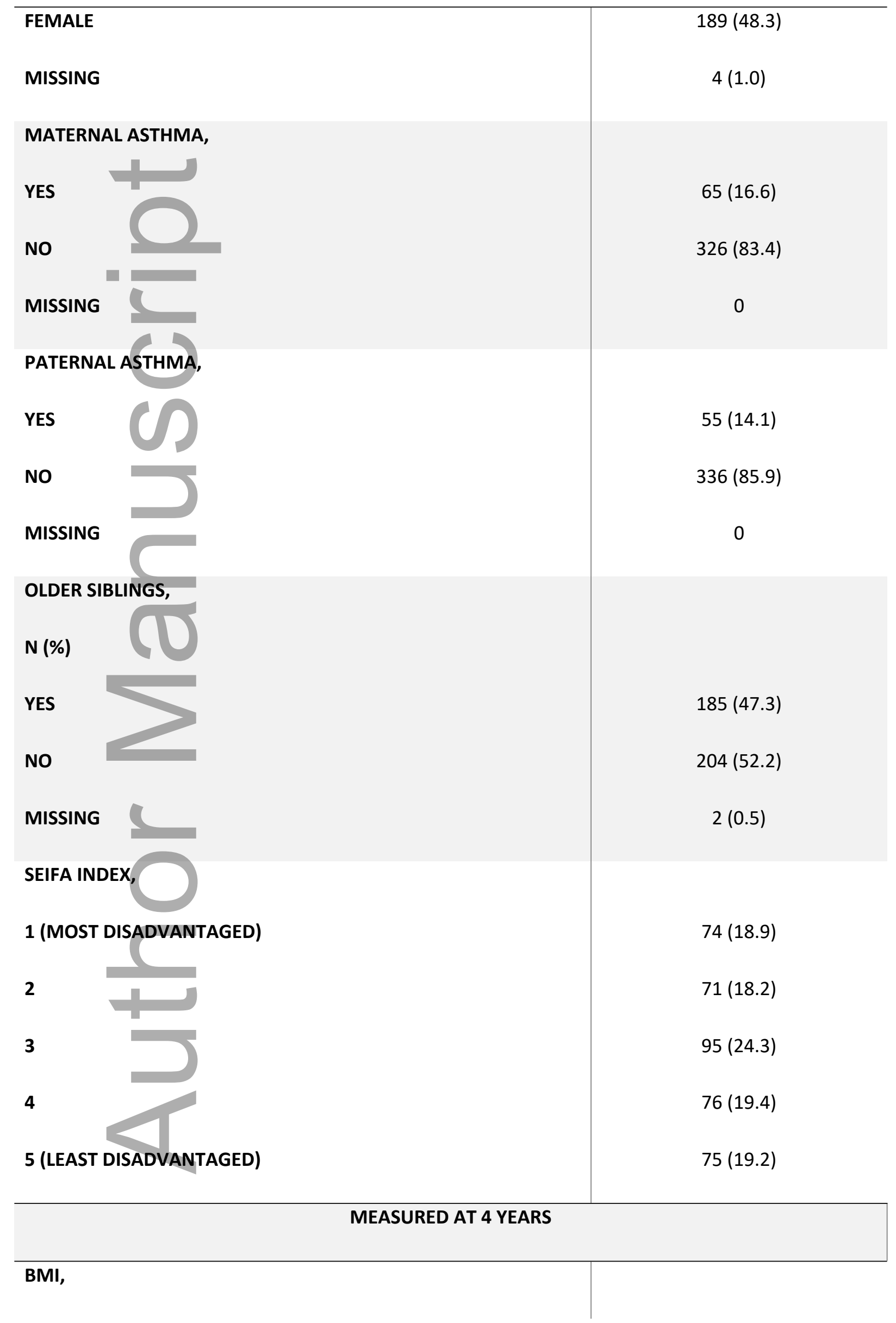

This article is protected by copyright. All rights reserved 


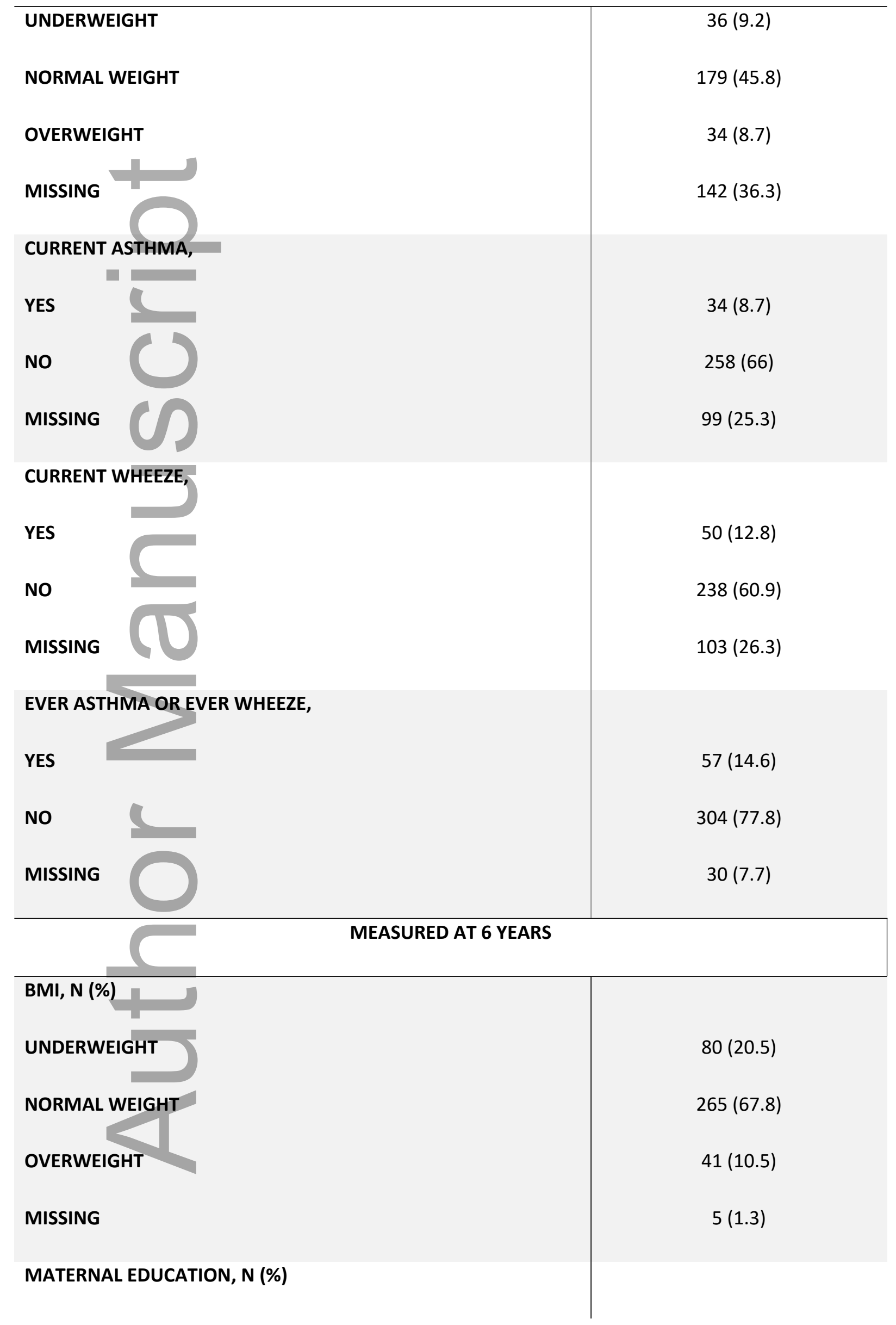

This article is protected by copyright. All rights reserved 


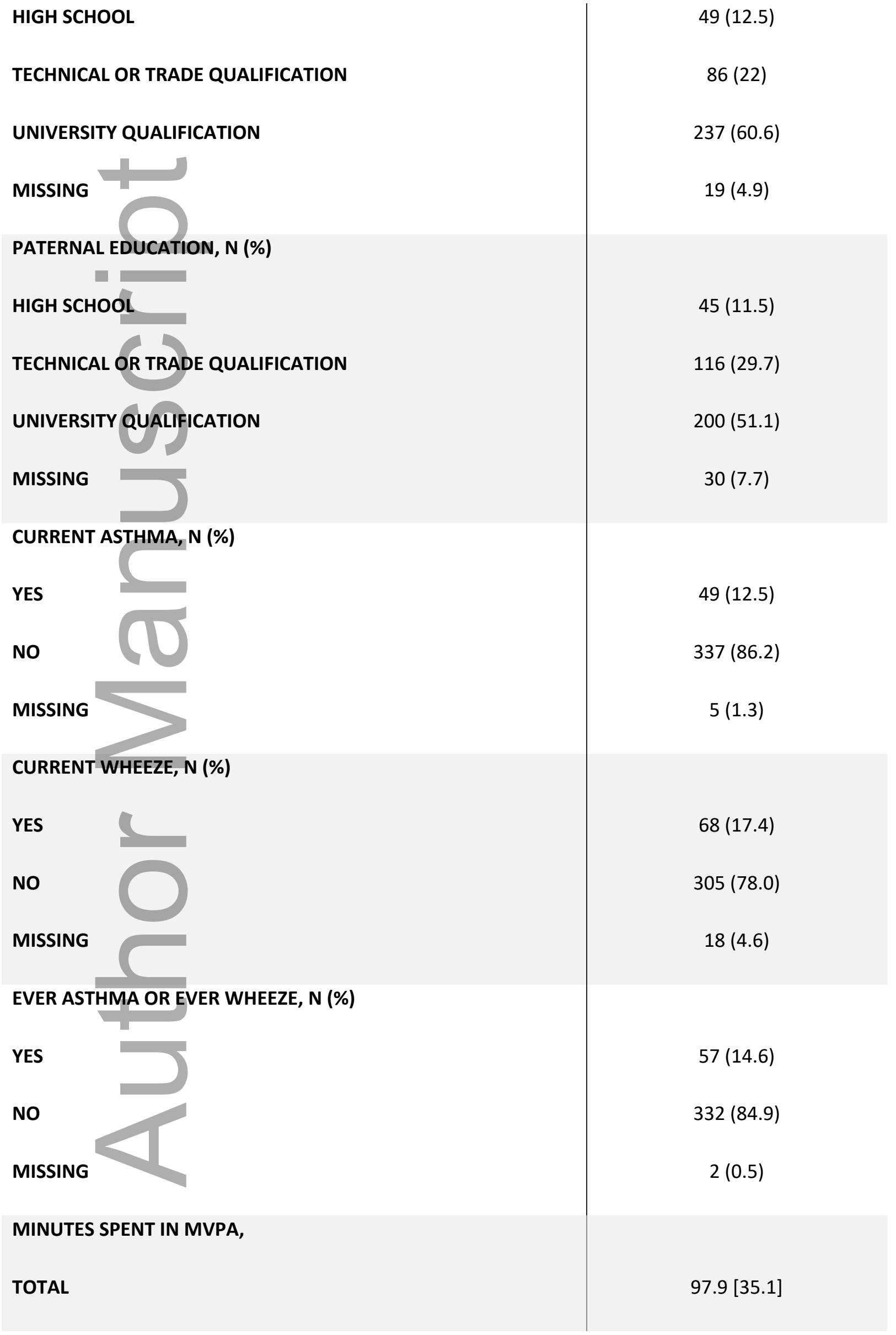

This article is protected by copyright. All rights reserved 
BOYS

$110.7[35]$

GIRLS

$84.8[30.3]$

MET WHO RECOMMENDATION FOR MVPA,

TOTAL

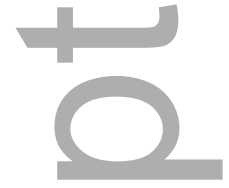

$346(88.5)$

BOYS

$188(94.9)$

GIRLS

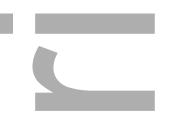

$154(81.5)$

SD - standard deviation; BMI - body mass index; SEIFA - Socioeconomic Indexes for Areas; MVPA - moderate to vigorous

311 physical activity

312 Table 2: Table of adjusted regression coefficients, 95\% confidence intervals for cross-sectional and longitudinal models and $p$ values for the likelihood ratio tests for interaction.

\begin{tabular}{|c|c|c|c|c|c|c|}
\hline 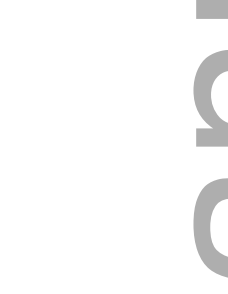 & $\begin{array}{c}\text { CURRENT } \\
\text { ASTHMA } \\
\text { COEFFICIENT } \\
(95 \% \mathrm{Cl})\end{array}$ & $\begin{array}{c}\text { P } \\
\text { VALUE }\end{array}$ & $\begin{array}{c}\text { CURRENT } \\
\text { WHEEZE } \\
\text { COEFFICIENT } \\
(95 \% \mathrm{Cl})\end{array}$ & $\begin{array}{c}\text { P } \\
\text { VALUE }\end{array}$ & $\begin{array}{l}\text { EVER WHEEZE } \\
\text { OR ASTHMA } \\
\text { COEFFICIENT } \\
\text { (95\% Cl) }\end{array}$ & $\begin{array}{c}\text { P } \\
\text { VALUE }\end{array}$ \\
\hline $\begin{array}{l}\text { LONGITUDINA } \\
\text { (EXPOSURE AT } \\
4 \text { YEARS) }\end{array}$ & $8.3(-5.6,22.1)$ & 0.24 & $5.8(-5.9,17.5)$ & 0.33 & $7.7(-4.8,20.2)$ & 0.23 \\
\hline $\begin{array}{l}\text { INTERACTION } \\
\text { WITH SEX }\end{array}$ & & 0.41 & & 0.51 & & 0.89 \\
\hline $\begin{array}{l}\text { CROSS- } \\
\text { SECTIONAL } \\
\text { (EXPOSURE AT } \\
6 \text { YEARS) }\end{array}$ & $2.9(-12.8,18.6)$ & 0.72 & $-1.3(-13.2,10.6)$ & 0.83 & $5.3(-7.4,17.9)$ & 0.41 \\
\hline $\begin{array}{l}\text { INTERACTION } \\
\text { WITH SEX }\end{array}$ & & 0.44 & & 0.39 & & 0.31 \\
\hline $\begin{array}{l}\text { INTERACTION } \\
\text { WITH } \\
\text { EXPOSURE }\end{array}$ & & 0.17 & & 0.59 & & 0.70 \\
\hline
\end{tabular}

This article is protected by copyright. All rights reserved 
STATUS AT AGE

4

314 Longitudinal models adjusted for sex, SEIFA, older siblings, maternal and paternal asthma and BMI at 4 years. Cross-

315 sectional models adjusted for sex, SEIFA, older siblings, maternal and paternal asthma, BMI at 6 years and the respective

316 exposure status at 4 years.

317 Figure legend: Figure 1: Flow of participants through the HealthNuts study.

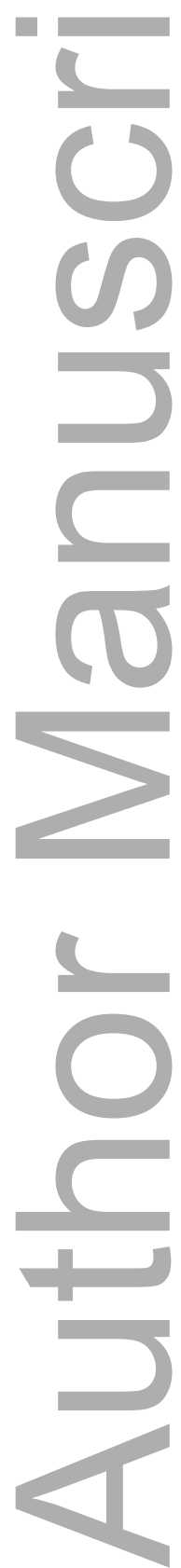

This article is protected by copyright. All rights reserved 


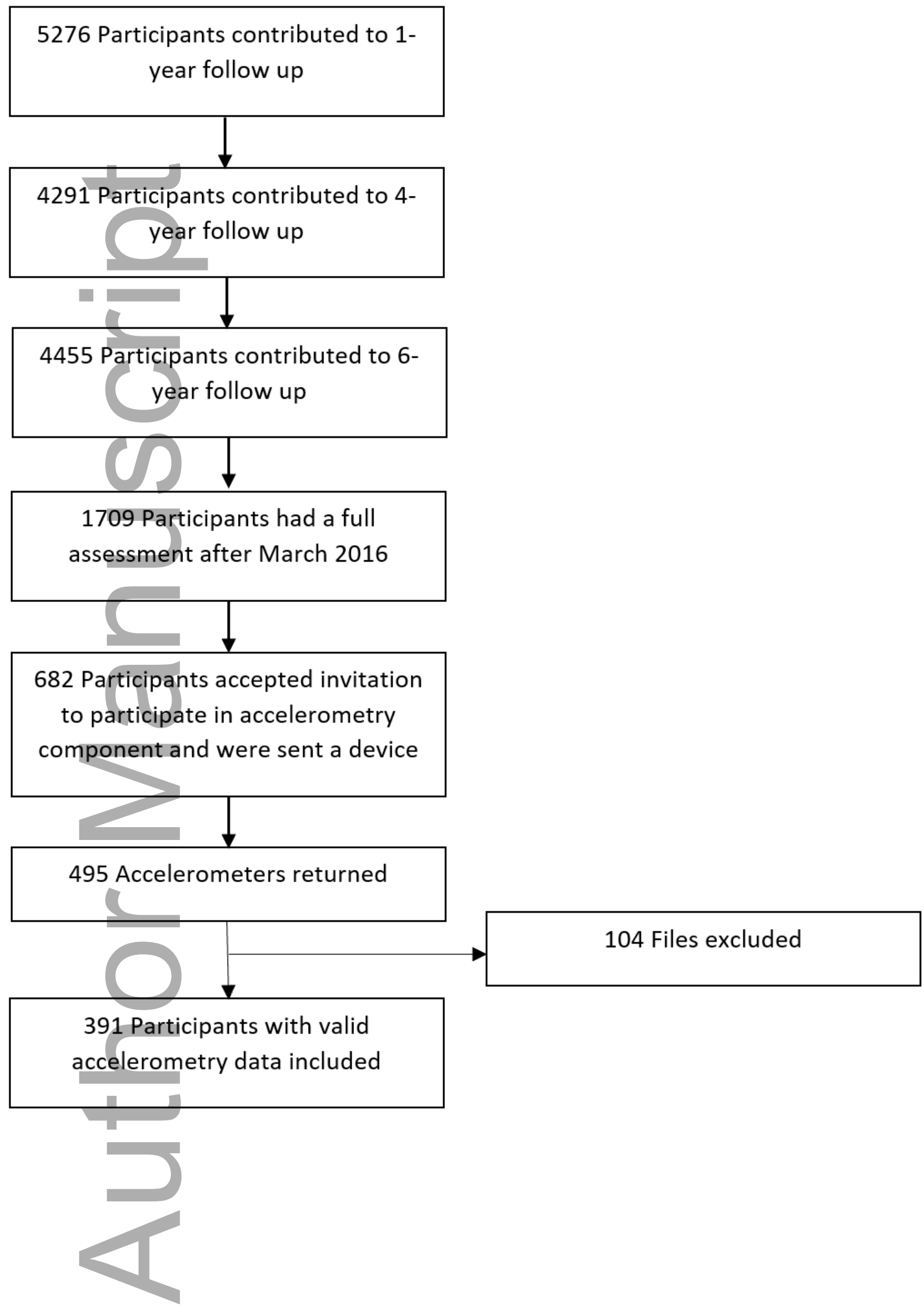

This article is protected by copyright. All rights reserved 


\section{University Library}

\section{- M M I E R R VA A gateway to Melbourne's research publications}

Minerva Access is the Institutional Repository of The University of Melbourne

\section{Author/s:}

Cassim, R;Dharmage, SC;Peters, RL

Title:

Are Young Children With Asthma More Likely to Be Less Physically Active?

\section{Date:}

2021-12-01

Citation:

Cassim, R., Dharmage, S. C. \& Peters, R. L. (2021). Are Young Children With Asthma More Likely to Be Less Physically Active?. PEDIATRICS, 148 (2), pp.S54-S55. https:// doi.org/10.1542/peds.2021-053843CCCC.

Persistent Link:

http://hdl.handle.net/11343/276460 